\title{
Numerical Assessment of In-Line Rotor-Stator Mixers in High-Shear Melt Conditioning (HSMC) Technology
}

\author{
GERARD SERGE BRUNO LEBON ${ }^{1,2}{ }^{1,2}$ JAIME LAZARO-NEBREDA, ${ }^{1}$ \\ JAYESH B. PATEL, ${ }^{1}$ and ZHONGYUN FAN ${ }^{1}$ \\ 1.--Brunel Centre for Advanced Solidification Technology (BCAST), Brunel University \\ London, Uxbridge UB8 3PH, UK. 2.—e-mail: Bruno.Lebon@brunel.ac.uk
}

\begin{abstract}
High shear melt conditioning technology refines the as-cast structure of light alloy melts, thereby improving the mechanical properties of the casting and reducing the occurrence of defects, without requiring chemical grain refiners. To upscale the technology and apply it to processes involving larger melt volumes, a computational fluid dynamics study is conducted with three rotorstator mixers operating in both batch and continuous modes. Analysis of the results show that rotor-stator mixers with smaller stator holes outperform those with larger ones because of larger shear rates-increasing the deagglomeration rate-and larger volume flow rates-increasing the dispersion of the intensively sheared melt in the bulk liquid. Compared with batch mode, continuous operation results in lower mass flow rate through the mixer and reduced mixing, although the mixer design has a larger impact on both measures.
\end{abstract}

\section{INTRODUCTION}

High shear melt conditioning (HSMC) technology results in improved thermophysical properties, extrudability, and machinability and reduces the occurrence of defects in the treated light alloy melt, ${ }^{1,2}$ without the addition of chemical grain refiners. The beneficial effects of HSMC are attributed to grain refinement by the deagglomeration of inclusions. ${ }^{3-5}$ Defect reduction is also explained by the deagglomeration of harmful oxide films. ${ }^{6}$ The advantage of HSMC over commercial grain refiners lies in the recyclability of the cast or wrought alloy due to the polluting grain refining constituents that cannot be readily removed once added.

HSMC consists of submitting a bulk volume of melt to an intense shearing field through a rotorstator mixer. A rotor rotates at high speed, typically of the order of 1000 RPM, thereby drawing the melt into the confined volume of a stator. The large velocity difference between the moving rotor blades and the fixed stator inner surface across the small gap between the rotor and the stator results in large shear rate values. Melt is ejected at high velocity through stator holes, with the shear rate being larger at the stator hole surface facing the leading edge of the rotor. ${ }^{7}$ The effect of the rotor-stator mixer operation is two-fold: (1) The large shear rates result in particle deagglomeration, thereby reducing the size of oxide films and other inclusions in the melt. ${ }^{8}$ (2) The large flow rate through the rotor-stator mixer redistributes the intensively sheared melt in the bulk of the mixing vessel. ${ }^{9,10}$

The flow pattern inside the melt bulk is pivotal to both dispersive and distributive processes and affects the efficiency of the mixer. This mixing zone, commonly referred to as a pseudo-cavern for shear thinning liquids, ${ }^{11}$ is of paramount interest in the study of rotor-stator mixers. ${ }^{12}$ Furthermore, the flow around the mixer is turbulent, complicating the optimization of the process. The high-speed rotor moves within the small gap and entrains melt, resulting in time-dependent flow features such as the high-speed jets ejected from the stator, trailing vortices inside the mixer, vortices below the rotor, and large re-circulation regions in the crucible. ${ }^{13}$ Optimization of HSMC necessitates understanding of the dynamics of mixing and the flow inside stirred vessels, calling for both experimental investigations ${ }^{12,14-16}$ and numerical simulations..$^{9,10}$

HSMC technology has proven successful in reducing grain sizes in direct-chill (DC) cast billets, ${ }^{1,4} \mathrm{a}$ process called melt-conditioned direct-chill (MCDC) casting, and in controlling the size of secondary 
Mixer A

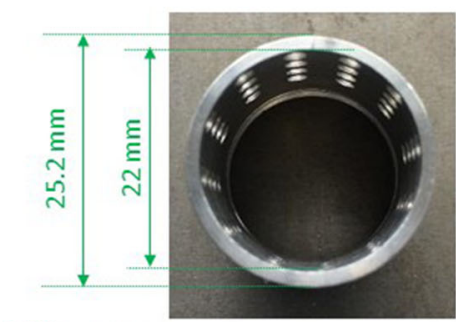

$0.25 \mathrm{~mm}$ gap

(rotor-stator)

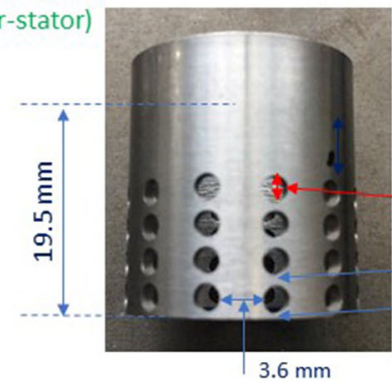

Mixer B
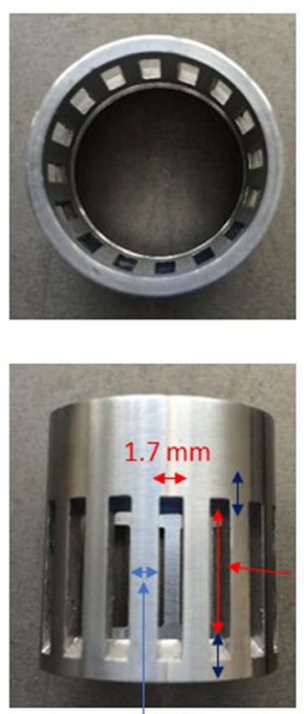

Mixer $\mathrm{C}$
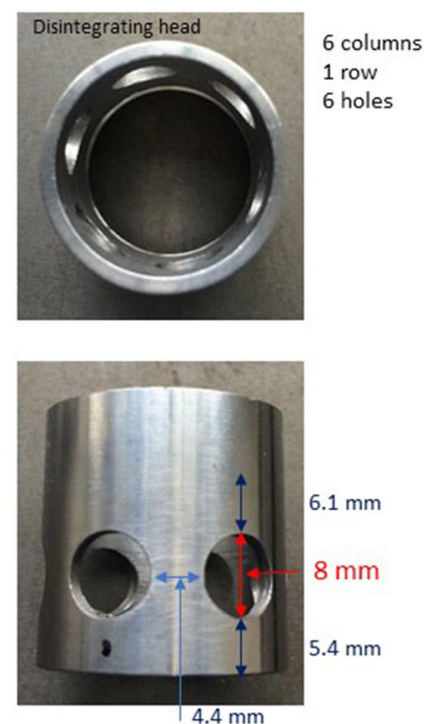

Fig. 1. Mixer heads used in this study.

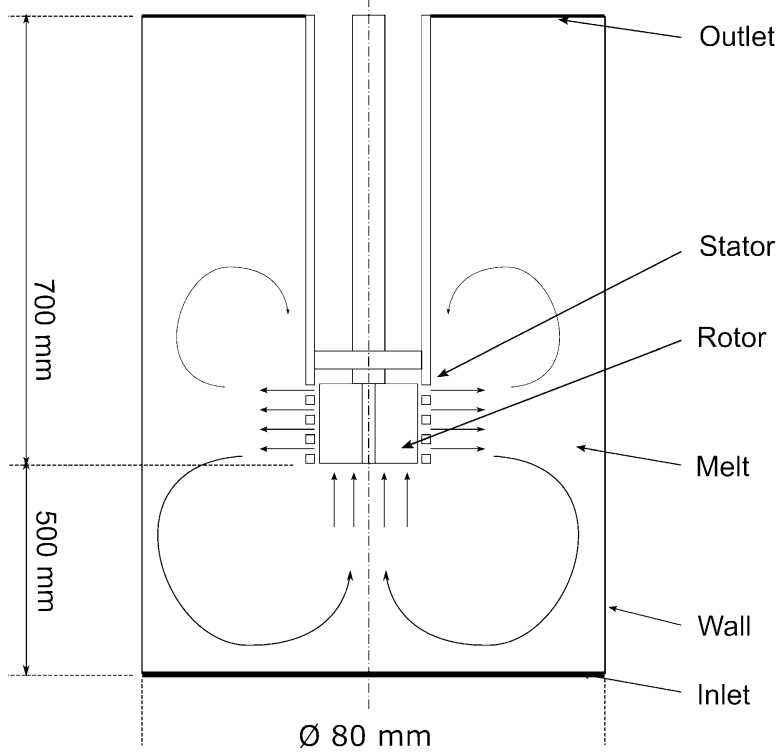

(a)

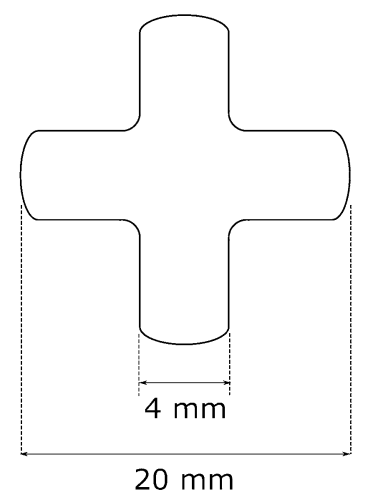

(b)

Fig. 2. (a) Modeling setup with mixer A shown as a vertical cross section $(y=0 \mathrm{~m})$. The mixer and wetted cylinder are concentric. The bottom of the mixer is located at $z=0 \mathrm{~m}$. The inlet is $0.05 \mathrm{~m}$ below, at $z=-0.05 \mathrm{~m}$, while the outlet is at $z=0.07 \mathrm{~m}$. The setups for mixers $\mathrm{B}$ and $\mathrm{C}$ are identical. (b) Geometry of the rotor.

dendrite arm spacings (SDAS). Widespread extension of HSMC to other continuous casting processes is desirable, with potential benefits including a decrease in per unit cost of production and enhanced homogeneity in the cast products. However, continuous operation introduces additional scaling difficulties. ${ }^{17}$ MCDC casting is special in that it is possible to introduce the intense shearing field directly inside the sump of a DC caster. This luxury is not afforded in other casting processes, where treatment must occur further upstream.

In this article, computational fluid dynamics (CFD) is employed to compare three rotor-stator mixers running in both batch mode and continuous, 
Table I. Boundary conditions for both batch and inline simulations

\begin{tabular}{|c|c|c|c|c|}
\hline Variable & Inlet & Outlet & Walls & Rotor blades \\
\hline Velocity $\boldsymbol{U}$ & $\begin{array}{l}\text { Dirichlet boundary condition } \\
\text { with a fixed value of Batch mode: } \\
\quad(0,0,0) \mathrm{m} \mathrm{s}^{-1} \\
\text { Inline mode: }(0,0,0.1) \mathrm{m} \mathrm{s}^{-1}\end{array}$ & $\begin{array}{c}\text { Neumann boundary } \\
\text { condition (zero normal } \\
\text { gradient) }\end{array}$ & $\begin{array}{l}\text { No slip bound- } \\
\text { ary, } U=0 \\
\quad \mathrm{~m} \mathrm{~s}^{-1}\end{array}$ & $\begin{array}{l}\text { Moving wall velocity set to } \\
0 \mathrm{~m} \mathrm{~s}^{-1} \text { relative to the } \\
\text { rotating frame }\end{array}$ \\
\hline Pressure $p$ & Neumann boundary condition & $\begin{array}{c}\text { Dirichlet boundary } \\
\text { condition with a fixed } \\
\text { value of } 0 \mathrm{~Pa}\end{array}$ & $\begin{array}{l}\text { Neumann } \\
\text { boundary con- } \\
\text { dition }\end{array}$ & $\begin{array}{c}\text { Neumann boundary condi- } \\
\text { tion }\end{array}$ \\
\hline $\begin{array}{l}\text { Turbulent } \\
\text { specific dissi- } \\
\text { pation } \omega\end{array}$ & Mixing length $l=0.0056 \mathrm{~m}$ & $\begin{array}{l}\text { Neumann boundary } \\
\text { condition }\end{array}$ & $\begin{array}{l}\omega \text { wall func- } \\
\text { tion } 19\end{array}$ & $\omega$ wall function 19 \\
\hline $\begin{array}{l}\text { Turbulent } \\
\text { viscosity ra- } \\
\text { tio } v_{t}\end{array}$ & Calculated, not prescribed & $\begin{array}{l}\text { Calculated, not pre- } \\
\text { scribed }\end{array}$ & $\begin{array}{l}v_{t} \text { wall function } \\
\text { as a function of } \\
\qquad k 18\end{array}$ & $\begin{array}{c}v_{t} \text { wall function as a func- } \\
\text { tion of } k 18\end{array}$ \\
\hline
\end{tabular}

Only the inlet boundary conditions for velocity differ between both modes: the prescribed velocity is $0 \mathrm{~m} \mathrm{~s}^{-1}$ for batch mode and $0.1 \mathrm{~m} \mathrm{~s} \mathrm{~s}^{-1}$ into the pipe for inline mode. The boundaries are indicated in Fig. 2. The walls include the outer surface of the wetted cylinder, the stator walls, and the rotor stop.

or inline, modes with a background flow of $0.1 \mathrm{~m} \mathrm{~s}^{-1}$ (corresponding to a Reynolds number Re of 8000). Since deagglomeration and mixing both depend on the flow conditions around the rotor-stator region, the velocity field, turbulent viscosity, shear rate, and flow rates through the mixer in both operating modes are compared. The effect of the turbulence model choice is assessed by comparing results from a Reynolds-averaged Navier-Stoke (RANS) model and a detached eddy simulation (DES) model.

\section{MODELING SETUP}

This study considers three rotor-stator mixers. The rotor is the same in all three configurations and is illustrated in Fig. 2b: it consists of four blades of $4 \mathrm{~mm}$ width and is of diameter $20 \mathrm{~mm}$ overall. The height of the rotor blades is $17.5 \mathrm{~mm}$. The three different mixer heads include: a four-row mixer with 12 small round holes each of $2.7 \mathrm{~mm}$ diameter (mixer A), a 16-slot mixer with each slot of $1.7 \mathrm{~mm}$ width and $11 \mathrm{~mm}$ height (mixer B), and a single-row mixer with 6 big round holes, each of $8 \mathrm{~mm}$ diameter (mixer C), all illustrated in Fig. 1 with their respective dimensions. The outer diameter of the mixers in the numerical model, $D$, is fixed to $25 \mathrm{~mm}$. The total hole area for each mixer is similar (roughly $300 \mathrm{~mm}^{2}$ ). The clearance (rotor-stator gap) is $1 \mathrm{~mm}$.

\section{COMPUTATIONAL FLUID DYNAMICS}

The open-source CFD package OpenFOAM (version 6$)^{18}$ was used to run the simulations. OpenFOAM uses the finite volume method to discretize the transient, three-dimensional flow conservation equations. Two turbulence models were considered in this study: the $k-\omega$ shear stress transport (SST) model $^{19}$ and a detached eddy simulation (DES) model. ${ }^{20}$ The unstructured mesh was generated using SALOME 9.4.0. ${ }^{21}$ The sliding mesh method, with an arbitrary mesh interface (AMI) between the rotor and stator cell regions, is used to simulate the rotation of the rotor blades.

The mixers are immersed in a wetted pipe of $80 \mathrm{~mm}$ inner diameter as shown in Fig. 2a. Each case is run for two configurations: a batch mode and for a continuous bulk flow with $R e=8000$ through the pipe. The rotor speed $N$ is varied from 1000 RPM to $5000 \mathrm{RPM}$ in steps of $1000 \mathrm{RPM}$.

Table I lists the boundary conditions. Only the inlet boundary conditions differ between the batch and inline cases. For the batch case, the prescribed velocity at the inlet is $0 \mathrm{~m} \mathrm{~s}^{-1}$, identical to a wall noslip boundary. For the inline mode, an inbound flow of $0.1 \mathrm{~m} \mathrm{~s}^{-1}$ normal to the inlet surface is prescribed. Standard outflow conditions were imposed at the outlet. The mesh density was fine enough at the walls to employ the selected turbulence models. The liquid properties were set to those of water with the density $\rho=1000 \mathrm{~kg} \mathrm{~m}^{-3}$ and kinematic viscosity $v=1.0 \times 10^{-6} \mathrm{~m}^{2} \mathrm{~s}^{-1}$. Water was chosen as it is a good physical analogue to aluminum melt. ${ }^{22,23}$ The transparency of water will allow validation of the model in experiments that are planned for the near future.

An implicit Euler first-order differencing scheme is used for time discretization. Convective terms were treated with the second-order linearupwind scheme. ${ }^{24}$ The selected implementation of the pressure-velocity coupling was the PIMPLE algorithm, which is a combination of PISO $^{25}$ and SIMPLE, ${ }^{26}$ with the SIMPLE algorithm being used 
Mixer A

(a) $\max 1.2 \mathrm{~m} / \mathrm{s}$

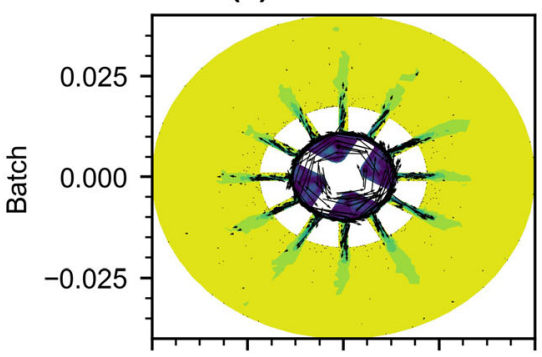

(d) $\max 1.3 \mathrm{~m} / \mathrm{s}$

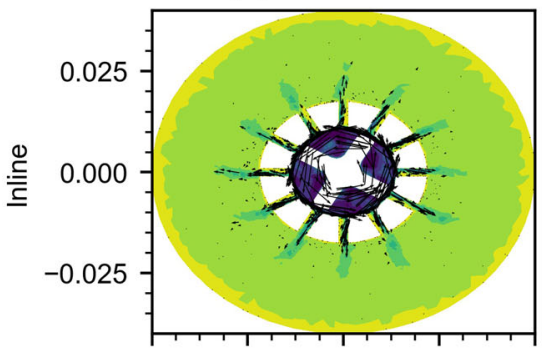

(g) $\max 0.63 \mathrm{~m} / \mathrm{s}$

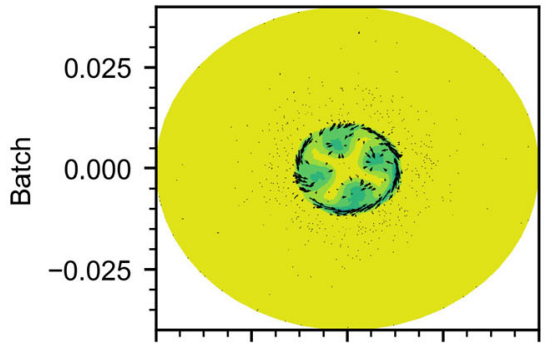

(j) $\max 0.35 \mathrm{~m} / \mathrm{s}$

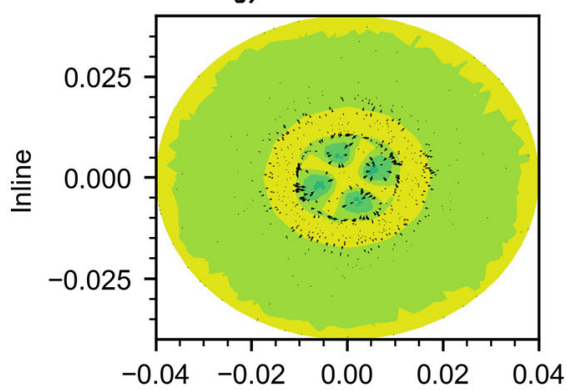

Mixer B

(b) $\max 1.3 \mathrm{~m} / \mathrm{s}$

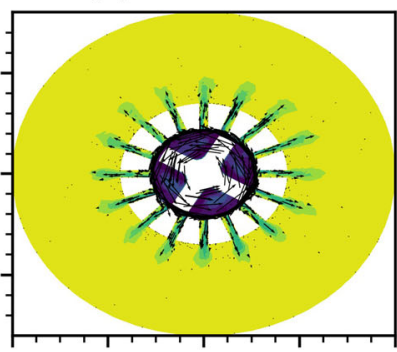

(e) $\max 1.3 \mathrm{~m} / \mathrm{s}$

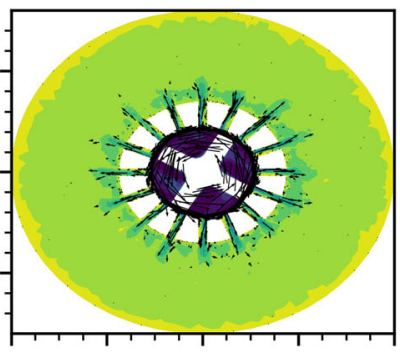

(h) $\max 0.61 \mathrm{~m} / \mathrm{s}$

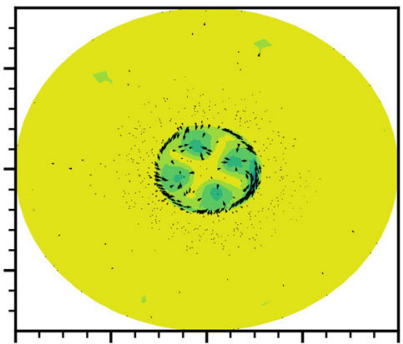

(k) $\max 0.39 \mathrm{~m} / \mathrm{s}$

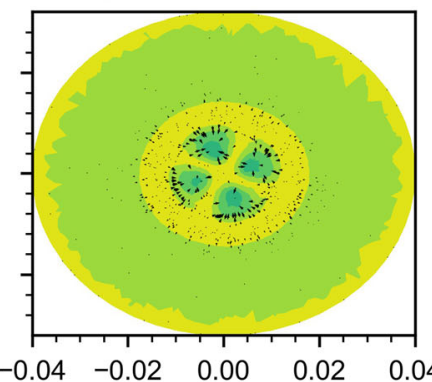

Mixer C

(c) $\max 1.3 \mathrm{~m} / \mathrm{s}$

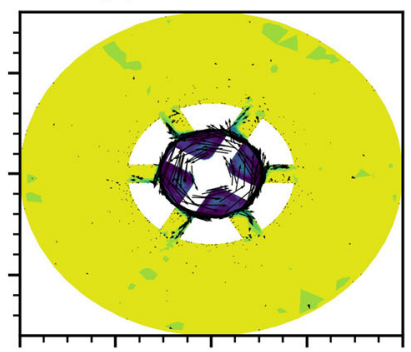

(f) $\max 1.3 \mathrm{~m} / \mathrm{s}$

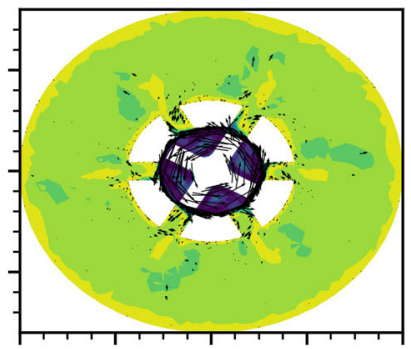

(i) $\max 0.71 \mathrm{~m} / \mathrm{s}$

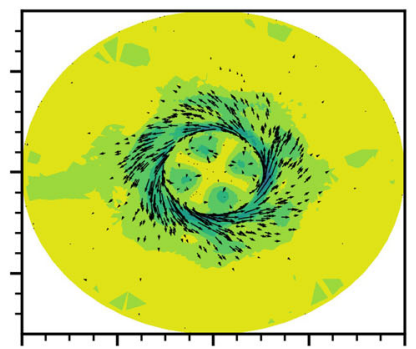

(I) $\max 0.62 \mathrm{~m} / \mathrm{s}$
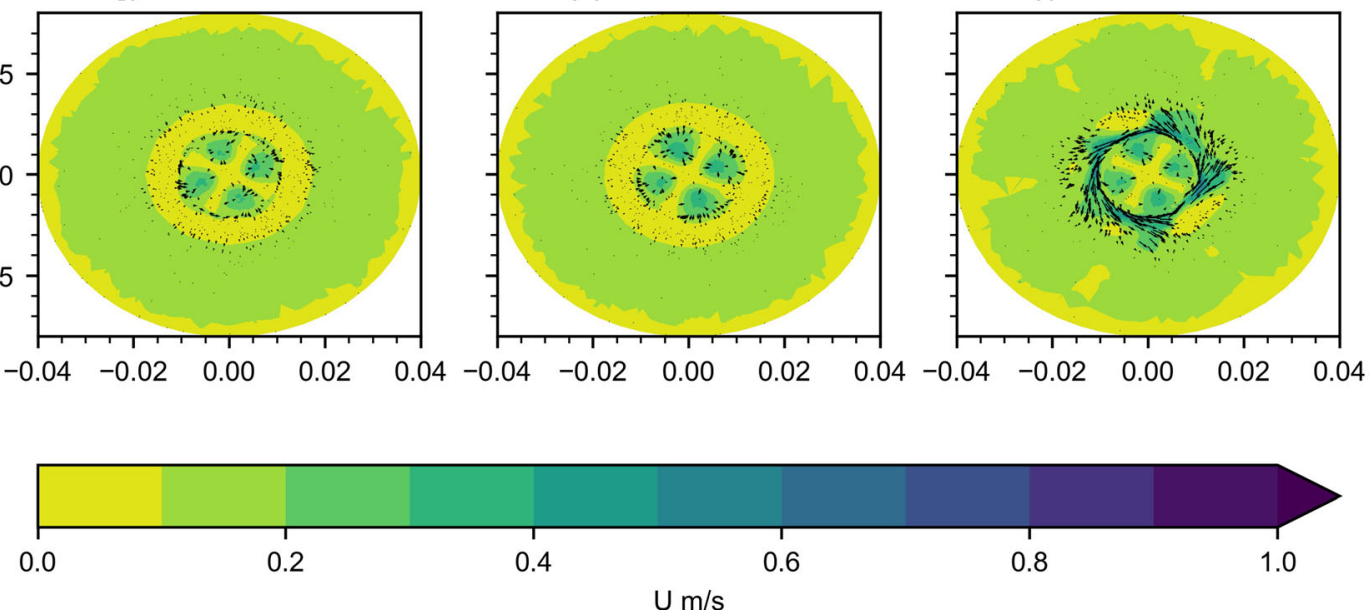

Fig. 3. Velocity $U$ contours along slice cutting through the fourth row in mixer $A$ (a and d) corresponding to $z=13 \mathrm{~mm}$ and mid-section of mixers $\mathrm{B}$ and $\mathrm{C}$ (b, c, e, and f) corresponding to $z=8.7 \mathrm{~mm}$ for a rotor speed of $1000 \mathrm{RPM}$, predicted using the $k-\omega$ SST turbulence model. (g-l) Corresponding horizontal section $1 \mathrm{~mm}$ below the bottom of the mixers. (a-c, $g-i)$ Batch mode and (d-f, j-I) continuous mode, as indicated by the row labels. The rotor moves anticlockwise. The values quoted in the sub-caption labels indicate the maximum contour value in the selected plane. 
Mixer A

(a) $\max 1.6 \times 10^{4} \mathrm{~s}^{-1}$

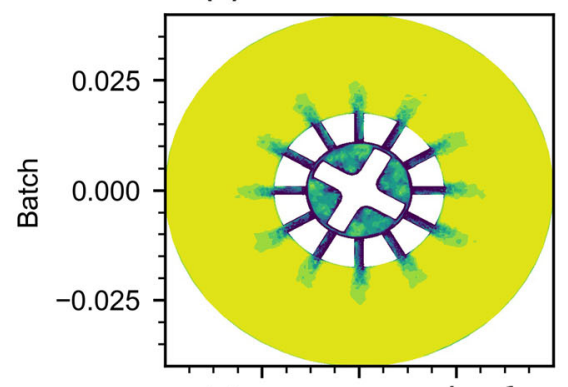

(d) $\max 1.8 \times 10^{4} \mathrm{~s}^{-1}$
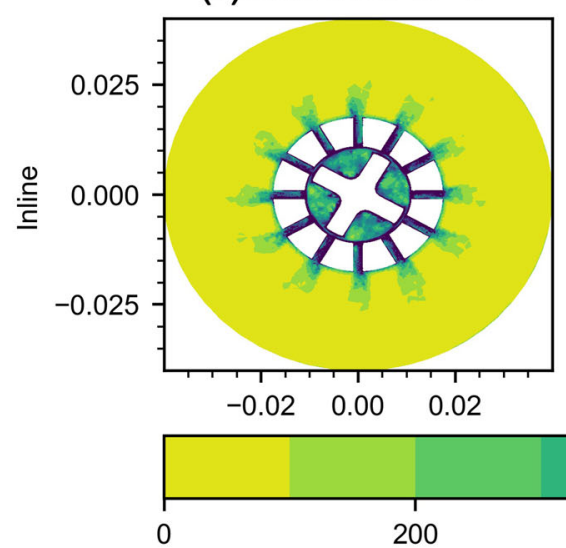

Mixer B

(b) $\max 2.2 \times 10^{4} \mathrm{~s}^{-1}$

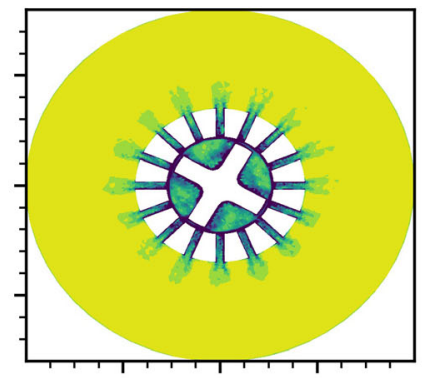

(e) $\max 2.3 \times 10^{4} \mathrm{~s}^{-1}$

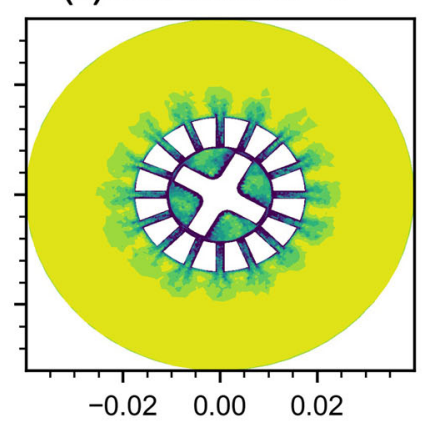

Mixer C

(c) $\max 1.8 \times 10^{4} \mathrm{~s}^{-1}$

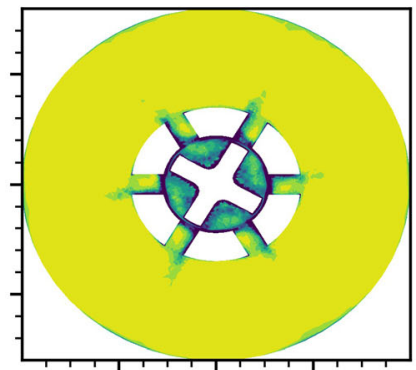

(f) $\max 1.8 \times 10^{4} \mathrm{~s}^{-1}$

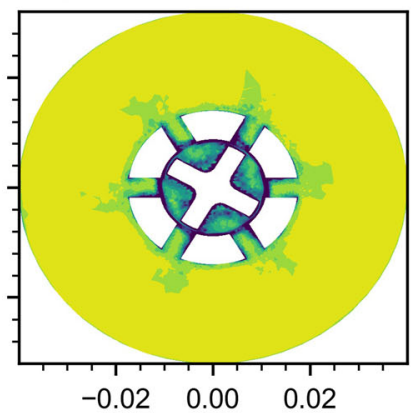

800

1000

Fig. 4. Shear rate $\dot{\gamma}$ contours along slice cutting through fourth row in mixer $\mathrm{A}$ ( $\mathrm{a}$ and $\mathrm{d}$ ) corresponding to $z=13 \mathrm{~mm}$ and mid-section of mixers $\mathrm{B}$ and $\mathrm{C}$ (b, c, e, and f) corresponding to $z=8.7 \mathrm{~mm}$ for a rotor speed of 1000 RPM, predicted using the $k-\omega$ SST turbulence model. (a-c) Batch mode and $(d-f)$ continuous mode. The values quoted in the subcaption labels indicate the maximum contour value in the selected plane.

within every time step and the iterations being out corrections: this implementation is available in OpenFOAM through the standard application pimpleFOAM. For numerical stability, an adaptive time step was used, where a maximum Courant number of 1.0 was enforced. An additional constraint on the time step size was the imposition of a maximum of a 1 degree turn for the rotor. This results in a maximum time step of $0.32 \mathrm{~ms}$ in the case of 1000 RPM, for example. Each simulation was run for a minimum of 65 rotor revolutions before analyzing the results.

\section{RESULTS AND DISCUSSION}

\section{Comparison Between Rotor-Stator Mixers}

The flow fields around the mixers are shown in Fig. 3. All contours correspond to a snapshot in time after 65 revolutions of the rotor. The velocity (magnitude) contours are plotted on horizontal slices along the following selected planes: $z=13$ $\mathrm{mm}$ for mixer A and $z=8.7 \mathrm{~mm}$ for mixers $\mathrm{B}$ and $\mathrm{C}$. For mixer A, most of the outflow occurred at the top row, hence, the selection of the velocity slice in that plane to show contours in Fig. 3.
The net flow through the mixer heads are all from the bottom opening and out of the stator holes. A low-pressure zone near the rotor blades drives the flow field, causing the liquid to be entrained from the bottom opening. Due to mass continuity, the liquid is forced out of the stator holes. The highpressure zones near the leading edges of the rotors-the foremost sections of the blades that push the melt as the rotor moves-cause an outward pressure gradient that forces the liquid out. Another consequence of the larger jet next to the leading edge is the presence of a recirculation at the trailing edge. The flow behavior is roughly similar for all mixers and so is the maximum predicted velocity in the mixer regions.

However, the melt recirculation below the mixers, shown in Fig. 3g, h, i, j, k, and l, exhibits greater differentiation between the flows produced by mixers $\mathrm{A}$ and $\mathrm{B}$ and mixer C. For mixers A and B, which both feature smaller individual stator holes, the rotary flow below the mixer opening is consistently smaller in magnitude than underneath mixer C. This smaller recirculation is desirable as, in high shear melt conditioning, it is preferable for most of the energy to be expended in deagglomerating intermetallic phases and oxides rather than them 
Mixer A

(a) $\max 23$

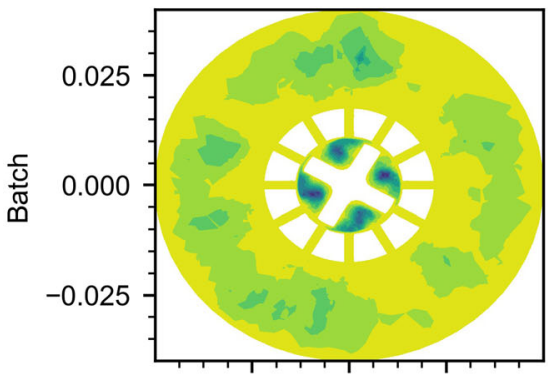

(d) $\max 22$
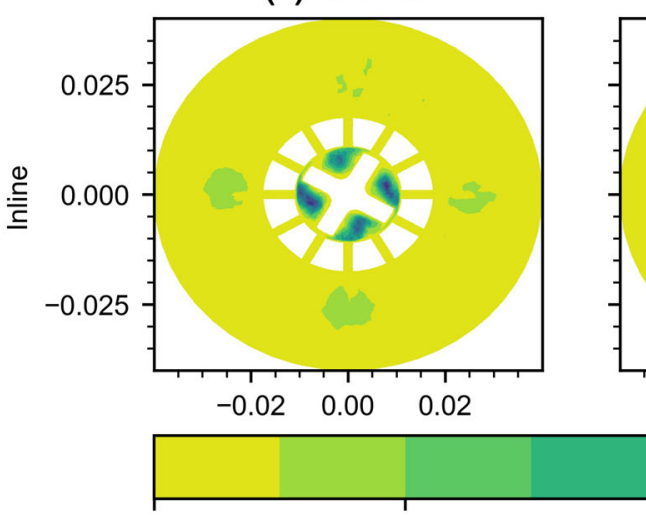

Mixer B

(b) $\max 26$

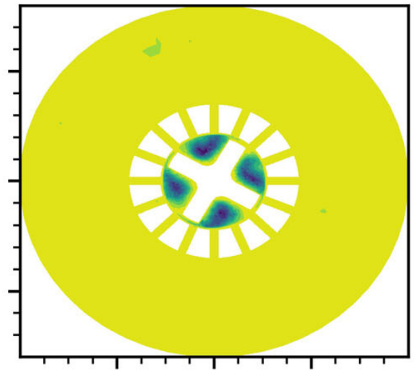

(e) $\max 21$

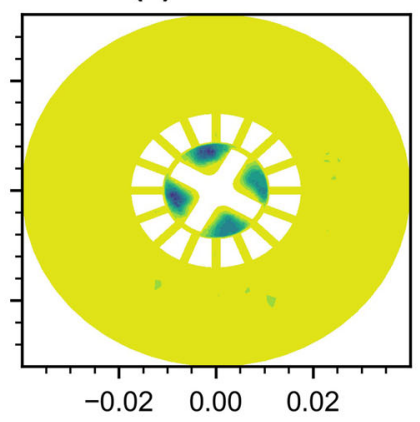

10
15

$v_{t} / v$
Mixer C

(c) $\max 30$

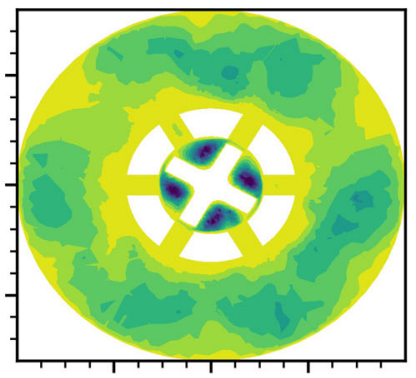

(f) $\max 30$

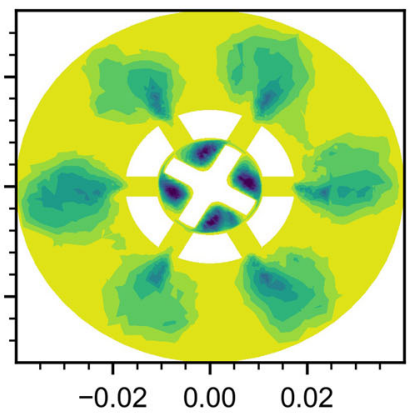

20

Fig. 5. Kinetic turbulent viscosity ratio $\left(v_{t} / v\right)$ contours along slice cutting through the fourth row in mixer $\mathrm{A}(\mathrm{a}$ and $\mathrm{d})$ corresponding to $z=13 \mathrm{~mm}$ and mid-section of mixers $B$ and $C(b, c, e$, and f) corresponding to $z=8.7 \mathrm{~mm}$ for a rotor speed of 1000 RPM, predicted using the $k-\omega$ SST turbulence model. $(a-c)$ Batch mode and $(d-f)$ continuous mode. The values quoted in the sub-caption labels indicate the maximum contour value in the selected plane.

being gently swayed around in helical motion along the channel. In MCDC casting, any larger recirculation of the bulk liquid would lead to a macrosegregation band due to forced solute transport, thereby harming the casting integrity, as exemplified by the lighter colored circular band in Fig. 3 in Ref. 27.

A similar study was conducted experimentally by Dybalska et al. in a larger water tank in batch mode, with their mixer labeled $\mathrm{RH}$ corresponding to mixer $\mathrm{A}$ in this study. ${ }^{23}$ Of interest in their work was the uniformity of the mixing below the mixer, as delimited by alumina powder patterns on the tank floor. The $\mathrm{RH}$ mixer performed worse in their uniformity measure than identical stators with square holes or using round holes but with successive rows in cross lines. However, this performance is less of a worry here as the present study is concerned with the possibility of treating the moving melt in a confined cylinder rather than in batch in a larger vessel. Nevertheless, the general jet pattern emanating from the mixer is similar to what was observed in their study.
The shear rate contours along the same horizontal sections (relative to the axis of the rotor) are shown in Fig. 4. Mixer B shows the best performance because of a combination of higher velocities in the stator holes and a larger number of stator holes per row. This mixer is therefore the most suited for disintegrating oxide agglomerates and intermetallic phases. The maximum shear rates all occur within the mixing volume, where particle deagglomeration is expected to occur. The shear rate is relatively unaffected by the presence of a forcing flow of $0.1 \mathrm{~m} \mathrm{~s}^{-1}$ in the inline mode, showing promise that continuous melt treatment at low volume flow rates is achievable.

However, this increased shear rate in mixer B is at the expense of redistributing sheared melt, with the design exhibiting the lowest turbulent viscosity in the bulk region as shown in Fig. 5. So far, the effect of a background flow around the mixer has been negligible in terms of velocity profiles and shear rates. However, the amount of turbulence mixing is radically reduced in continuous mode as shown by the low viscosity values outside the mixer 
Mixer A

(a) $\max 22$

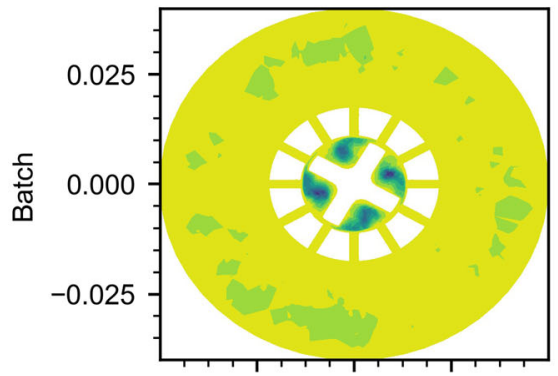

(d) $\max 22$
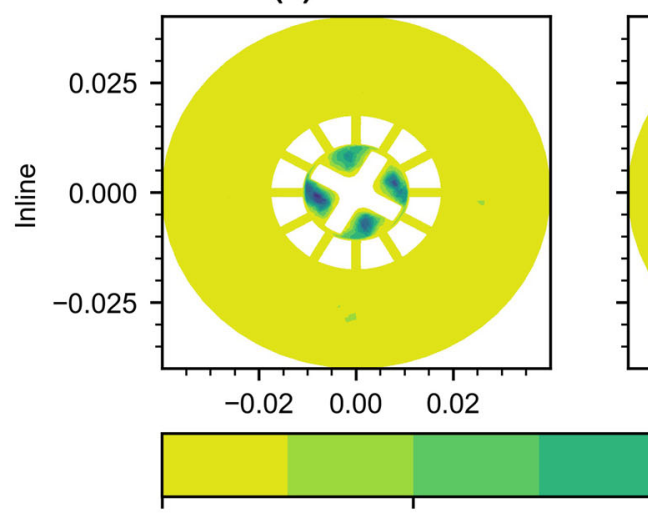

Mixer B

(b) $\max 20$

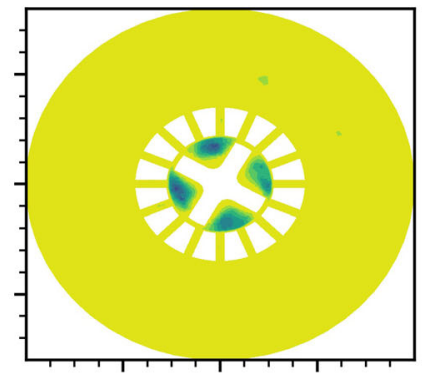

(e) $\max 20$

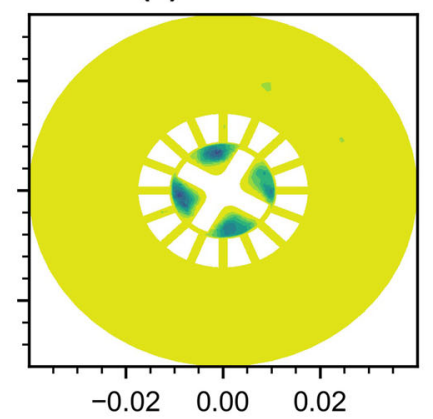

Mixer C

(c) $\max 29$

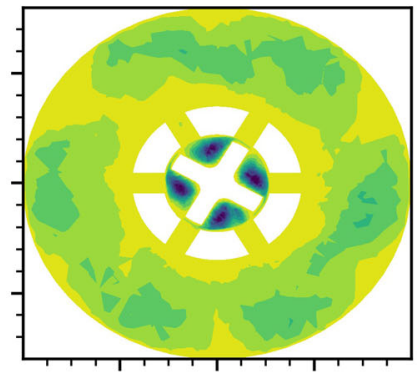

(f) $\max 30$

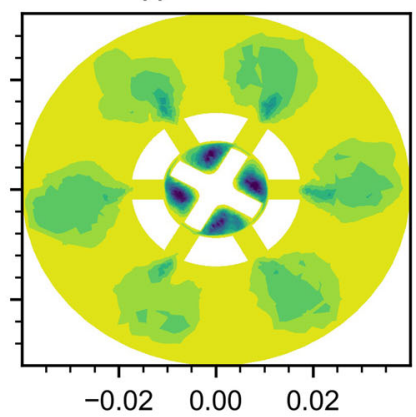

$$
0
$$

5

10

15

$v_{t} / v$

Fig. 6. Kinetic turbulent viscosity ratio $\left(v_{t} / v\right)$ contours along slice cutting through the fourth row in mixer $\mathrm{A}(\mathrm{a}$ and $\mathrm{d})$ corresponding to $z=13 \mathrm{~mm}$ and mid-section of mixers $\mathrm{B}$ and $\mathrm{C}(\mathrm{b}, \mathrm{c}, \mathrm{e}$, and $\mathrm{f}$ ) corresponding to $z=8.7 \mathrm{~mm}$ for a rotor speed of $1000 \mathrm{RPM}$, predicted using the DES $k-\omega$ SST turbulence model. $(\mathrm{a}-\mathrm{c})$ Batch mode and $(\mathrm{d}-\mathrm{f})$ continuous mode. The values quoted in the subcaption labels indicate the maximum contour value in the selected plane.

region in Fig. 5d, e, and f, consistent with what has been observed in the literature. ${ }^{28}$ The mixing zone is also confined to the height of the rotor stator mixer. Mixer $\mathrm{C}$ outperforms the other mixers in this measure.

\section{Effect of the Turbulence Model Choice}

The effect of the turbulence model choice on the flow predictions is adumbrated in this section. Figure 6 shows the predicted kinetic turbulent viscosity ratio using the same conditions as in the preceding section, the only difference being the application of the detached eddy simulation (DES) model. ${ }^{20}$ The predicted mixing zone sizes do not deviate significantly from the RANS results, indicating that the computationally more affordable RANS model offers a good compromise between accuracy and speed for the study of inline rotorstator mixers as applicable to melt processing. This is especially attractive in the design of experimental studies that attempt to optimize the melt conditioning process with regards to deagglomeration and redistribution of sheared melt or upscaling studies that employ mixers of different geometries and sizes.

\section{Effect of Rotor Speed}

The simulations were conducted for faster rotor speeds of 2000 RPM, 3000 RPM, 4000 RPM, and $5000 \mathrm{RPM}$, and the mass flow rates through the rotor stator mixers were computed. Figure 7 shows the variation of mass flow rate as a function of rotor speed. The performances of mixers A and B are again comparable, with mixer $\mathrm{C}$ demonstrating the weakest performance. The continuous mode of operation, denoted by $0.1 \mathrm{~m} / \mathrm{s}$ in the legend, results in a slightly degraded performance as expected. ${ }^{17}$

The net flowrate passing through the stator holes, $Q$, depends on a flow number $N_{Q}$, as given in the relationship

$$
N_{Q}=\frac{Q}{N D^{3}} .
$$

$D$ is the mixer diameter. This relationship is valid for both batch and continuous modes. ${ }^{17}$ The legend of Fig. 7 shows the relative values of the flow numbers for each configuration. The slight degradation in the mass flow rate through mixers A and B is shown quantitatively. While still degraded upon usage in continuous mode, mixers $\mathrm{A}$ and $\mathrm{B}$ still outperform mixer $\mathrm{C}$ in batch mode: the mixer 


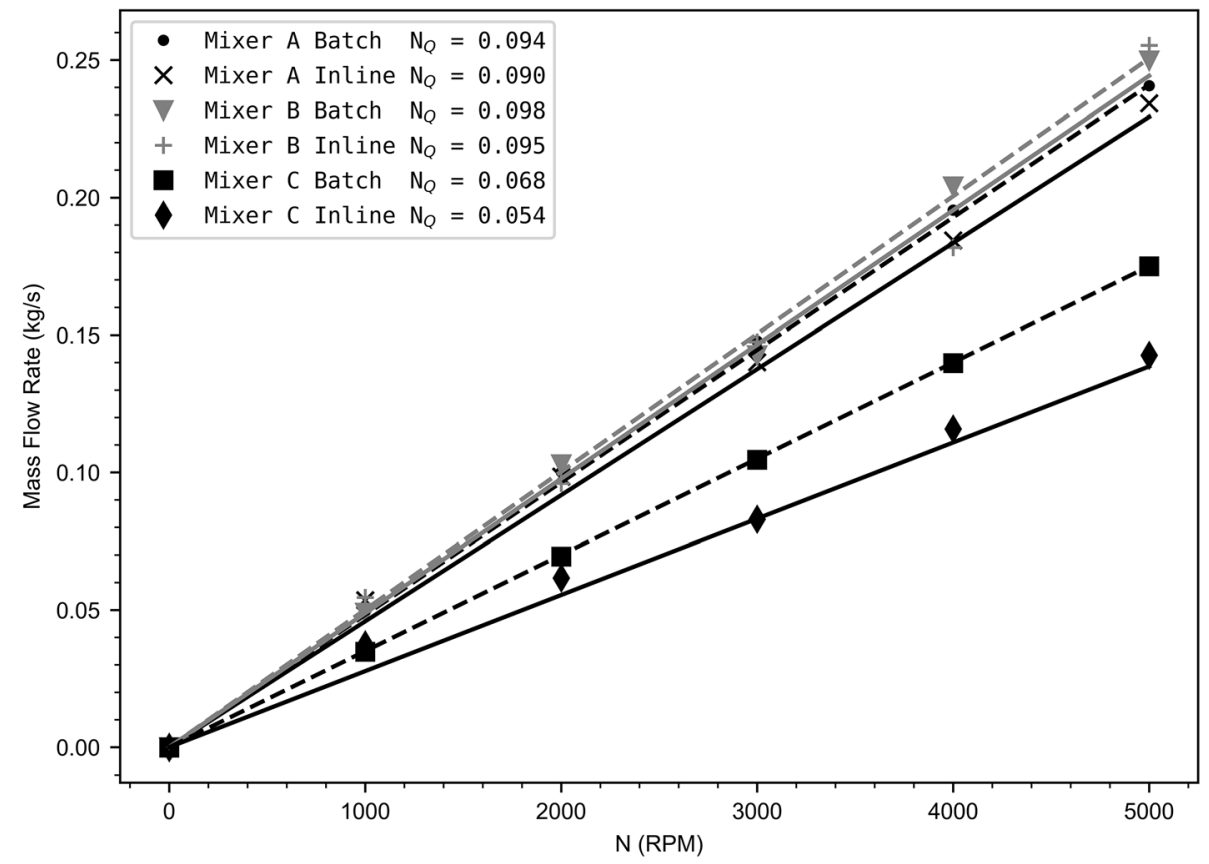

Fig. 7. Mass flow rates through the rotor-stator mixer as a function of rotor speed. The markers denote the computed mass flow rate values for the last cycle of the CFD simulations and the lines are the least squares regression through the data points. The flow rate number $N_{Q}$ for each configuration is given in the legend.

geometry is hence the determining parameter that affects a rotor-stator mixer performance.

\section{CONCLUSION}

The performances of three rotor stator mixers were assessed via numerical modeling. The mixers with smaller stator holes are predicted to provide a better performance in deagglomerating oxide particles, although they are less suited for redistributing the melt in the liquid bulk. Choosing between a RANS or DES turbulence model is inconsequential for the prediction of rotor-stator performance. When operating in continuous mode, the performance of the rotor-stator mixers degrades slightly, with lower predicted turbulent mixing values and mass flow rates through the mixers. However, the degradation in performance upon operating mixers with smaller openings in continuous mode is less severe than what would be the case upon choosing a mixer with large openings.

\section{ACKNOWLEDGEMENTS}

Financial support from the Engineering and Physical Sciences Research Council (EPSRC), UK, under Grant Number EP/N007638/1 is gratefully acknowledged.

\section{DATA AVAILABILITY}

The datasets generated during and/or analyzed during the current study are available from the corresponding author on reasonable request.

\section{CONFLICT OF INTEREST}

The authors declare that they have no conflict of interest.

\section{OPEN ACCESS}

This article is licensed under a Creative Commons Attribution 4.0 International License, which permits use, sharing, adaptation, distribution and reproduction in any medium or format, as long as you give appropriate credit to the original author(s) and the source, provide a link to the Creative Commons licence, and indicate if changes were made. The images or other third party material in this article are included in the article's Creative Commons licence, unless indicated otherwise in a credit line to the material. If material is not included in the article's Creative Commons licence and your intended use is not permitted by statutory regulation or exceeds the permitted use, you will need to obtain permission directly from the copyright holder. To view a copy of this licence, visit $h$ ttp://creativecommons.org/licenses/by/4.0/.

\section{REFERENCES}

1. H.-T. Li, P. Zhao, R. Yang, J.B. Patel, X. Chen, and Z. Fan, Metall. Mater. Trans. B 48, 2481 (2017).

2. Y. Zhang, J.B. Patel, J. Lazaro-Nebreda, and Z. Fan, JOM 70, 2726 (2018).

3. Z. Fan, Y. Wang, M. Xia, and S. Arumuganathar, Acta Mater. 57, 4891 (2009).

4. S. Jones, A.K. Prasada Rao, and Z. Fan, Trans. Indian Inst. Metals 66, 117 (2013).

5. H. Men, B. Jiang, and Z. Fan, Acta Mater. 58, 6526 (2010).

6. J. Campbell, Metall. Mater. Trans. B 37, 857 (2006). 
7. A.T. Utomo, M. Baker, and A.W. Pacek, Chem. Eng. Res. Des. 86, 1397 (2008).

8. M. Tong, S.C. Jagarlapudi, J.B. Patel, I.C. Stone, Z. Fan, and D.J. Browne, IOP Conf. Ser. Mater. Sci. Eng. 84, 012092 (2015).

9. M. Tong, J.B. Patel, I. Stone, Z. Fan, and D.J. Browne, Comput. Mater. Sci. 131, 35 (2017).

10. G.S.B. Lebon, H.-T. Li, J.B. Patel, H. Assadi, and Z. Fan, Appl. Math. Model. 77, 1310 (2020).

11. L. Doucet, G. Ascanio, and P.A. Tanguy, Chem. Eng. Res. Des. 83, 1186 (2005).

12. A. Dybalska, Understanding and Development of High Shear Technology for Liquid Metal Processing (London: Brunel University, 2016).

13. S.L. Yeoh, G. Papadakis, and M. Yianneskis, Chem. Eng. Res. Des. 82, 834 (2004).

14. A. Dybalska, D. Eskin, and J.B. Patel, JOM 69, 720 (2017).

15. A. Dybalska, D.G. Eskin, and J.B. Patel, JOM 70, 1256 (2018).

16. H.H. Mortensen, F. Innings, and A. Håkansson, Chem. Eng. Res. Des. 121, 245 (2017).

17. A. Håkansson, Processes 6, 32 (2018).

18. H.G. Weller, OpenFOAM (OpenCFD Ltd (ESI Group), 2018),

19. F.R. Menter, M. Kuntz, and R. Langtry, in Turbulence, Heat and Mass Transfer 4 (Begell House, Antalya, Turkey, 2003), pp. 625-632.

20. M. Strelets, in 39th Aerospace Sciences Meeting and Exhibit (American Institute of Aeronautics and Astronautics, Reno, NV, U.S.A., 2001).
21. A. Ribes and C. Caremoli, in 31st Annual International Computer Software and Applications Conference - Vol. 2 (COMPSAC 2007) (IEEE, Beijing, China, 2007), pp. 553564.

22. I. Tzanakis, G.S.B. Lebon, D.G. Eskin, and K.A. Pericleous, Ultrason. Sonochem. 34, 651 (2017).

23. A. Dybalska, D.G. Eskin, and J. B. Patel, in Materials Processing Fundamentals 2019, edited by G. Lambotte, J. Lee, A. Allanore, and S. Wagstaff (Springer International Publishing, Cham, 2019), pp. 181-192.

24. R.F. Warming and R.M. Beam, AIAA J. 14, 1241 (1976).

25. R.I. Issa, J. Comput. Phys. 62, 40 (1986).

26. L.S. Caretto, A.D. Gosman, S.V. Patankar, and D.B. Spalding, in Proceedings of the Third International Conference on Numerical Methods in Fluid Mechanics, edited by H. Cabannes and R. Temam (Springer Berlin Heidelberg, Berlin, Heidelberg, 1973), pp. 60-68.

27. J.B. Patel, H.T. Li, M.X. Xia, S. Jones, S. Kumar, K. O'Reilly, and Z.Y. Fan, Mater. Sci. Forum 794-796, 149 (2014).

28. A. Håkansson, D. Arlov, F. Carlsson, and F. Innings, Can. J. Chem. Eng. 95, 806 (2017).

Publisher's Note Springer Nature remains neutral with regard to jurisdictional claims in published maps and institutional affiliations. 